spects. It is not always practicable, and it should be remembered that the physical attributes of a husband and wife are not always passed on to their children. It would seem more appropriate to us to match only the broad outlines of physical appearance in terms of height and stature.

All of our donors are screened in terms of a series of medical and laboratory tests and are also paid at the rate of $£ 4$ for each sample of semen they provide. Most are university students and are thus assumed to be of reasonable intelligence. The couple requiring insemination are asked to make a contribution of between $£ 5$ and $£ 10$ into a research fund administered by the local treasurer under our control. This is used to pay the donors. Under normal circumstances the payment covers a woman for up to six consecutive monthly inseminations. It is our impression that the fertility potential of frozen semen is less than that of the fresh.

Knowledge of the service has quickly spread and we now have a substantial waiting list of nearly 200 couples either undergoing investigation, waiting for treatment, or having insemination. We note that various authors have reported variable chances of success. The following facts might prove interesting:

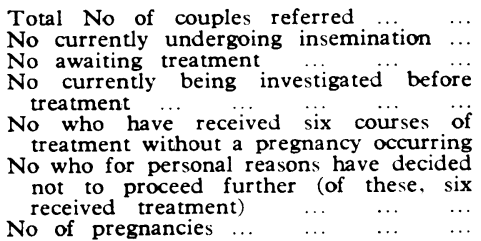

Excluding those patients who have not yet finished their course of treatment (23) it is apparent that 20 pregnancies have occurred, while 25 have had six courses of treatment without pregnancy. If in addition the six who received treatment and do not wish to proceed further are taken into consideration, it is apparent that the 20 pregnancies have occurred from 51 treated women, an approximate $40 \%$ success rate. An analysis in greater detail is now being carried out and it is hoped to publish this in the near future.

G W Pennington SANDRA NAIK

Sheffield and Region Endocrine Investigation Centre, Jessop Hospital for Women,

Sheffield

SIR,-I was interested in your leading article on AID (4 October, p 2). Very little has been published because of the sensitive nature of this work, and the impression is given that this is a new concept when in fact we are already treating second-generation AID women.

The lack of information has also created the impression that this procedure is relatively unsuccessful. In practice there is little difficulty in achieving a pregnancy by this method in normally fertile women; $49 \%$ of my patients conceived within three months of treatment, 412 pregnancies being achieved with an average of 4.4 inseminations. Of the first 100 patients, 58 have returned for a second baby, two are expecting a third, and one has four children.

\section{Sterilisation of minors}

SIR,-Your legal correspondent (27 September, $p$ 775) urges legislation to assist doctors in this difficult area. Mr William Nash, legal officer of the National Council of Civil Liberties, who acted for Mrs Hamidi in the case of the Sheffield girl, also pointed out that "there is a clear gap in the law which must be filled."

As a possible solution to this lacuna in the law we would like to bring to your attention the proposal made by the Second International Conference on Voluntary Sterilisation and recently endorsed and amended by the law panel and central medical committee of this federation. It reads as follows:

Applicable to incompetents-The following shall apply with respect to any person who does not have legal capacity to consent: if the parents or guardian of such a person and a physician have decided that temporary measures will be ineffective, they may apply for a procedure to render that person permanently infertile to a Board, duly appointed by the appropriate authority, which may, after full consideration, grant their application. ... The Board shall consist of at least five persons, both lay and professional of both sexes, which shall act by a majority vote. The Board shall also include a person or persons representative of the particular ethnic, religious or philosophical group of which the person who is the subject of the application is a member.'

We hope that the above suggestions will be constructive in the formulation of guidelines with respect to irreversible sterilisation until such time as fully reversible sterilisation methods are developed. We note that the use of injectable steroids and oral contraceptives can be valuable in such cases.

Rebecca J COOK MALCOLM POTTS

International Planned Parenthood Federation,

London SW1

Survival of infants with unoperated myeloceles

SIR,-It is interesting to read the experience of $\operatorname{Dr} M F$ Robards and his colleagues in Liverpool that $30 \%$ of the infants denied early closure of their myeloceles survived at least a year (4 October, $p$ 12). This is very different from the findings reported from Oxford, ${ }^{1}$ where 92 of 99 infants with unoperated myeloceles had died within the first year. Subsequent experience in Oxford and Swindon has shown a similar outcome in the unoperated group.

The outcome clearly varies from centre to centre and perhaps it is worth considering why this might be. As one who has been associated with a very low survival rate I should like to outline a personal approach to the care of such infants.

If, after discussion as fully as possible with the parents, surgeon, and family doctor, it is agreed that early surgery is not in the baby's best interest the hospital undertakes to provide care. It is unusual for the parents to ask to take the baby home, although, of course, they are free to do so. It would be wrong to ask for standards of nursing care to be in any way less than for any other infant. So the back wound is dressed and general care given. Nothing is done to prolong the infant's life. The infant is fed on demand but is not given tube feeds or parenteral nutrition. Antibiotics are not pre- scribed. I am prepared to sedate the baby when necessary. Most of these infants die with minimal suffering to them and their family. The cause of death has more often been infection than hydrocephalus in our experience.

I am well aware of the difficult moral and ethical area into which I venture. However, this approach, which is, I believe, similar to that carried out by many paediatricians, does have the support of our colleagues who nurse these babies and, above all, satisfies the demands of the parents that their grossly handicapped infant "shall not suffer."

St Mary's Hospital,

DAVID W HIDE

Newport, Isle of Wigh

Hide, D W, Williams, $M$ P, and Ellis, $M$ L, Developmental Medicine and Child Neurology,
$1972,14,304$.

\section{Tibial shaft fractures}

SIR,-Your leading article on tibial fractures (4 October, p 4) glosses over the important problem of skin cover which bedevils a small proportion of these injuries. As the blood supply below the knee is relatively poor and no loose skin is available there is a temptation to suture under tension, particularly if damaged skin has been excised. There is a basic conflict-namely, that the wound is lacerated and should not be closed primarily but the fracture is compound and should be converted into a simple one. If the fracture is unstable the temptation to introduce some form of hardware is almost irresistible.

I would like to take this opportunity to ask those who carry out the primary care and are unable for one reason or another to obtain assistance with difficult repairs to spare a thought or two for those who may be called in later to salvage limbs in the event of breakdown: (1) A single pedicle flap will probably slough, leaving two problems instead of one. A double pedicle flap is safer but moves very little. (2) The application of a closed plaster for some weeks in the presence of skin of doubtful viability may be followed by skin breakdown, suppuration, and necrosis of exposed bone. A window must be cut to allow wound inspection during the first few days. (3) A decision whether or not to use a cross-leg or muscle flap should be made within 48 hours of injury if possible-certainly within the first week. Skin-graft-covered muscle flaps are useful in small defects with minimal muscle damage, particularly in the over-40s for primary or secondary repair. (4) In unstable fractures I agree that a method of fixation which allows the knee to bend, gives access to the wound, and avoids introducing foreign material into the fracture site should be chosen.

Plastic and Jaw Department,

B S CRAWFORD Royal Hospital Annexe.

Fulwood. Sheffield

SIR,-It is a pity that, in an otherwise wellbalanced leading article (4 October, p 4) you should perpetuate a myth. It is just not true that encirclage wires "act like a tourniquet on the bone, interfering with local blood supply and delaying or preventing union." When encirclage wires fail, as in the case of tibial fractures they usually will, it is because they have been applied too loosely or with- 